\title{
Individual tourism information support in the regions of Russia
}

\author{
Daniil Babkov, Dinara Kuznetsova, and Natalia Surkova \\ Moscow Automobile and Road Construction State Technical University (MADI), Leningradsky \\ Avenue, 64, 125319 Moscow, Russian Federation
}

\begin{abstract}
Increasing the volume of tourism in the regions of Russia, improving the quality of tourist services provided, creating new, original, and non-standard tourist brands are urgent tasks for Russian regions, especially in modern conditions of increasing interest in domestic tourism. To solve such important problems, it is necessary to use modern technologies for creating an information space, popular means of communication, the development of modern digital environments that allow consumers of tourism services not only conveniently and individually receive, but also to take part in the creation of original content about various thematic attractions in the country's regions. The use of mobile applications should ensure full and diverse satisfaction of the mass demand of individual tourists, thus increasing the sustainable interest of tourism in all regions of Russia.
\end{abstract}

\section{Introduction}

Tourism today is a global business in which many areas of economic activity are involved the largest transport companies and airlines, service enterprises and hotel chains, travel corporations around the world. The countries of Europe and North America have built a significant part of their wealth on income from international tourism - the multiplier effect is $15 \%$ to $20 \%$ of GDP [1]. According to the World Travel \& Tourism Council (WTTC), by the end of 2018, the contribution of the tourism sector to global GDP grew by $3.1 \%$ to USD 7.2 trillion.

Russia has a huge potential for the development of domestic and inbound tourism. The geopolitical position of the country as part of the European and Asian continents is precisely the factor that allows preserving its tourist identity and attractiveness to tourists from all over the world. The natural and cultural-historical diversity of Russia makes it possible to develop almost all types of tourism: recreational, cultural and educational, business, sports, healthimproving, ecological, etc. The tourist potential of Russia lies in the diversity of climatic zones and landscapes and the history of the country that arouses a keen interest, not to mention the richest cultural heritage (from painting and music to literature and religion). Nevertheless, Russia lags far behind, receiving income from international tourism in conjunction with related industries of only $4 \%$ to $6 \%$ of GDP [1]. Regions and cities of Russia lose billions of rubles denying tourism support. Besides, hundreds of thousands of potential jobs are lost. 
Today, tourism is primarily a brand offering. The number of brands of domestic tourist routes famous all over the world since Soviet times is next to nothing: Karelia, Baikal, White Nights in Leningrad, the Golden Ring of Russia. One of the factorsof the competitiveness of the Russian industry of international and domestictourism is comprehensive information support of the sights of the Russian Federation, from hidden advertising in feature films and television films to the use of modern information technologies in the industry, including such as mobile cross-platform applications that allow offering tourists flexible and individual services such as the following:

- compilation of individual routes on selected themes;

- a description of all attractions located at a given distance from a specific point from the tourists' location;

- detailed and targeted description of the existing transport logistics along the selected route.

Creation of a digital environment that is friendly and understandable for tourists does not require additional and/or complex equipment. On the contrary, it is familiar to the modern "cultural" tourist on the principle of "being handy", filled with content on interesting, nonstandard and diverse individually oriented points of interest, different small towns, corners, cities and regions of Russia will increase the stability of interest in tourism in the regions of the country, especially within the individual and inexpensive, and, accordingly, mass tourism [2].

The creation of a digital environment that is friendly and understandable for tourists does not require additional and/or complex equipment. Filled with interesting, non-standard, and various relevant content about the sights of different places, hideaways, cities, and regions of Russia it will increase the sustainability of interest in tourism in the regions of the country, especially in individual, inexpensive and, accordingly, massive tourism.

The simplest and most effective solution is a mobile cross-platform application that allows not only receiving the required information in an easy and convenient form but also, if desired, adding one's impressions as additional description of attractions.

\section{Models and methods for increasing the sustainable interest in individual tourism in the regions of Russia}

The idea is so obvious that many of such applications have been developed before and are being developed today. It makes no sense to describe their operation in detail (Table 1 shows the result of the comparison). All have their advantages, but these applications have common disadvantages - first, limited functionality, which, in fact, simply replaces the huge paper guides that were popular and most importantly necessary at a time when the Internet and information in it were not spread as they are today.Second, the lack of the ability for users to fill in information about attractions in the form of photos and text reviews themselves.

As a result of the analysis of development requirements, the following concept of the developed software product was formed:

- the developed software product must have access to existing software environments that store texts and photographs of landmarks taken earlier;

- $\quad$ easy access and work with maps of the area and websites for describing and booking hotels should also be organized;

- at the same time, its proprietary database should be developed, which will store specific data, such as addresses and coordinates of points of interest, their descriptive information, characteristics, and notes;

- the client part, first of all, should be available to the user anywhere in the region, and this is precisely the possibility that the features of mobile applications can provide; 
- users also participate in filling points of interest with content, for which they need to have the ability to upload their information to the application;

- it is necessary to provide a serverless way of transferring information between the application and the database, which will be allowed by the technology of cloud storage [3].

Table 1. Comparison of existing analogs

\begin{tabular}{|l|l|l|l|l|l|l|l|}
\hline \multirow{2}{*}{} & \multicolumn{7}{|c|}{ Application name } \\
\cline { 2 - 9 } & $\begin{array}{l}\text { Red } \\
\text { igo }\end{array}$ & $\begin{array}{l}\text { «Aro } \\
\text { und the } \\
\text { world» }\end{array}$ & $\begin{array}{l}\text { World } \\
\text { Explo- } \\
\text { rer }\end{array}$ & $\begin{array}{l}\text { Mo } \\
\text { mo } \\
\text { do } \\
\text { Plac } \\
\text { e }\end{array}$ & $\begin{array}{l}\text { Tripo } \\
\text {-so }\end{array}$ & $\begin{array}{l}\text { Top } \\
\text { Trip } \\
\text { Tip } \\
\text { Russia }\end{array}$ & $\begin{array}{l}\text { Ulmon } \\
\text { Rome }\end{array}$ \\
\hline Data oriented on Russia & + & - & - & - & + & + & - \\
\hline Search engine availability & + & - & + & - & - & + & + \\
\hline Phrasebook availability & - & + & - & - & - & - & + \\
\hline $\begin{array}{l}\text { General background } \\
\text { information }\end{array}$ & + & + & + & - & - & + & - \\
\hline Cloud data storage & - & - & - & - & - & - & - \\
\hline Offline mode & - & + & - & + & - & - & - \\
\hline $\begin{array}{l}\text { Working with foreign } \\
\text { tourists }\end{array}$ & - & + & - & + & + & - & + \\
\hline $\begin{array}{l}\text { Various interesting } \\
\text { information }\end{array}$ & + & - & + & + & - & - & + \\
\hline Dynamic route building & - & - & - & + & + & - & - \\
\hline $\begin{array}{l}\text { Interesting and user- } \\
\text { friendly interface }\end{array}$ & + & + & - & - & - & - & + \\
\hline Route planning & + & - & - & - & + & - & - \\
\hline $\begin{array}{l}\text { Individual request } \\
\text { customization }\end{array}$ & - & - & + & - & - & - & - \\
\hline Wide range of locations & - & - & + & - & - & - & + \\
\hline $\begin{array}{l}\text { Diverse and unique } \\
\text { routes }\end{array}$ & - & + & - & + & - & - & + \\
\hline
\end{tabular}

Thus, the structure of the software product being developed (Fig. 1) includes not only a mobile application (named «PathFinder») but also a cloud-oriented database and interaction with the mobile application.

\section{Results and Discussion}

The Firebase Realtime Database is a cloud-based NoSQL database that allows storing and synchronizing data between users in real-time. ThedatainitisstoredinJSONformat [4]. It has its own set of SDK (software development kit) tools, which allows software specialists to create applications for a specific software package, take advantage of each platform and reduce the time for integration [5]. Real-time sync allows users to access their data from any device, web or mobile, and this helps users to collaborate and cloud storage also. When users go offline, the Realtime Database SDK uses a local cache on the device to serve and save changes. When the device connects to the network, the local data is automatically synchronized. Firebase allows conveniently storing media data in the cloud by distributing and accessing the diverse data the app requires [6]. 


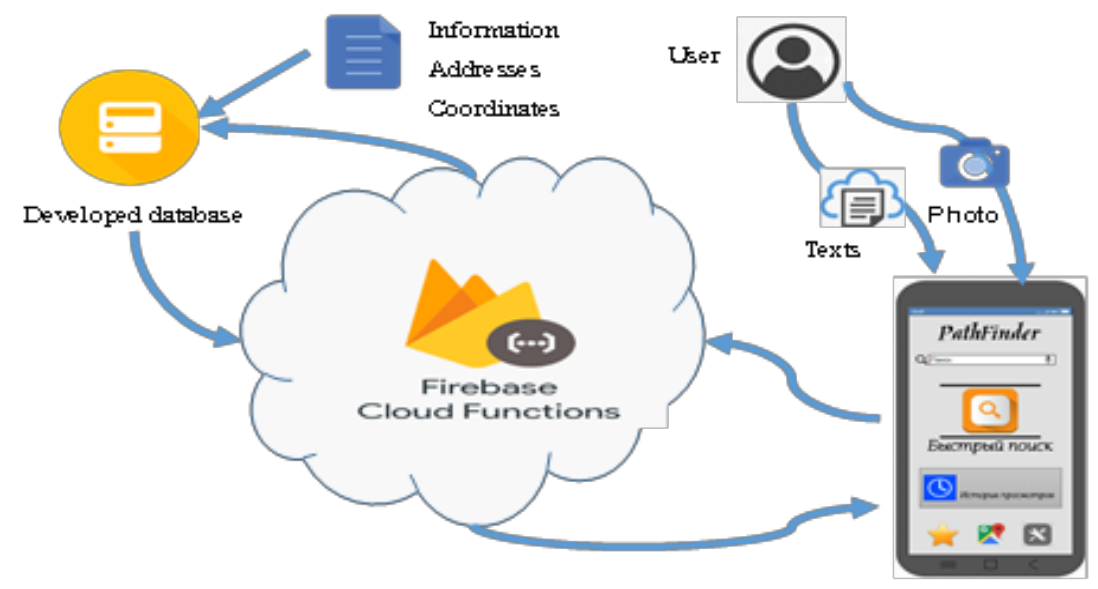

Fig. 1. Conceptual diagram of the developed software product

The developed database allows adding the following data for structured storage (Fig. 2):

- points of interest - which is a collective expression denoting all possible architectural, geological, social, etc. objects that may interest the user during a tourist trip or an ordinary walk:

- means of transportation - possible ways to get to the point of interest;

- ready route.

The «PathFinder» mobile application is developed in the Firebase Storage environment within the Firebase Database, which has all the necessary functions, is easy to maintain and learn, offers the developer a high level of security provided by Firebase Authentication, as well as the capabilities provided by the Firebase Realtime Database[6,7].

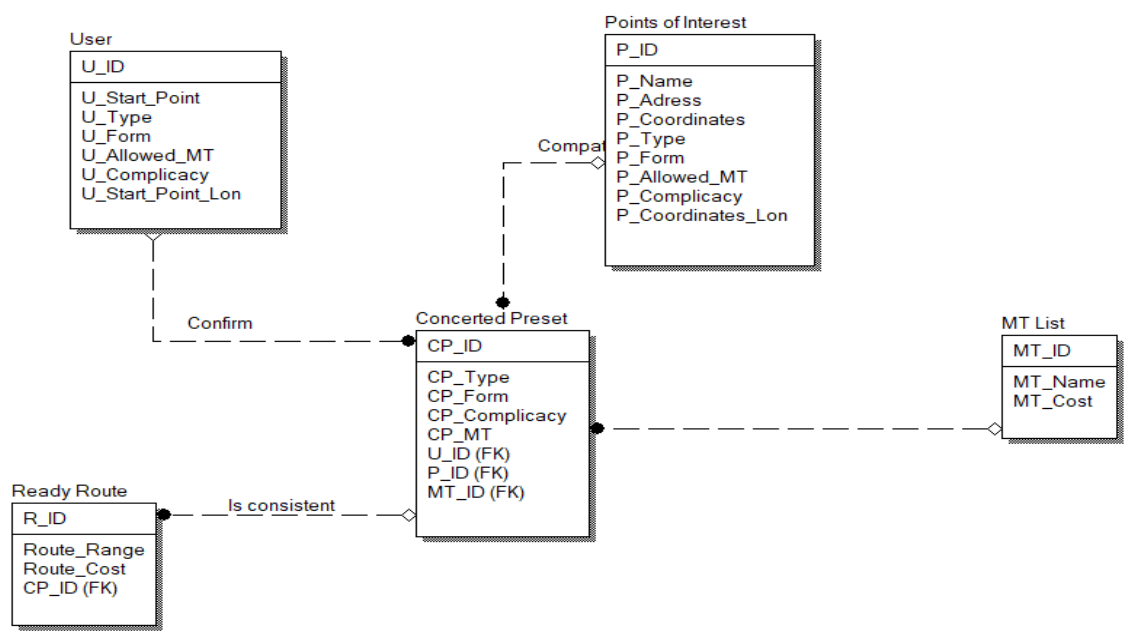

Fig. 2. Database model (IDEF1X notation) [8]

The developed application allows searching for a point of interest according to personal and other variouspreferences, receiving information on a description selected from the list of results obtained in the form of a video clip, from the gallery of imagessupplemented by users, audio accompaniment, historical information, descriptive information, information for 
orientation and tourist rating (Fig. 3). If desired, it will build a route to the point of interest, indicating the possible types of transport, time, and cost of travel.

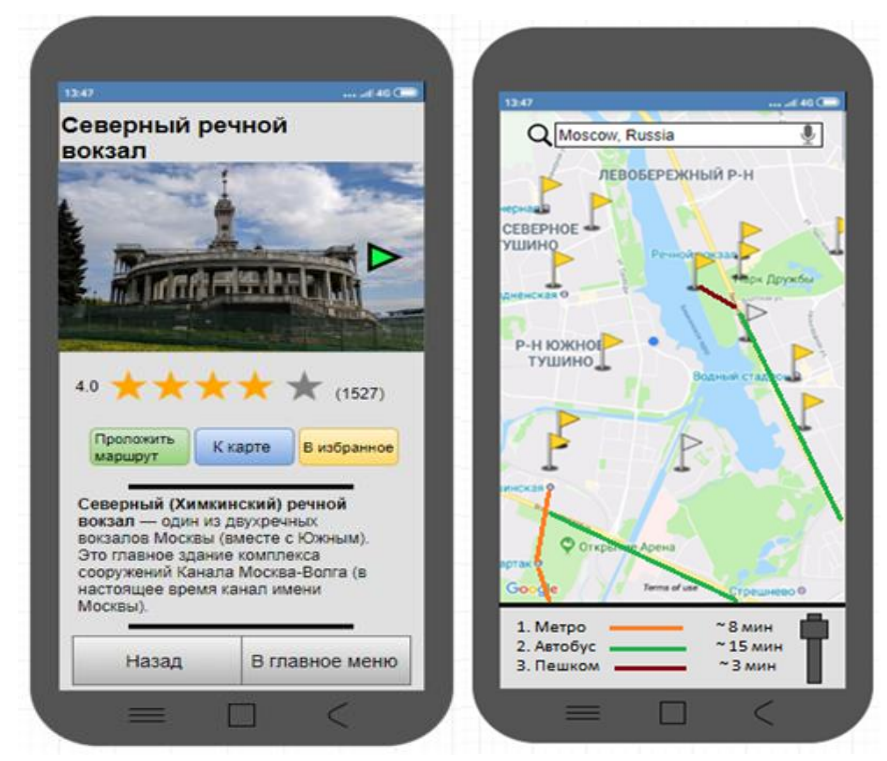

Fig. 3. An example of the "PathFinder" mobile application screen

Using cloud technologies provided by Google Inc. in the form of a Firebase Realtime Data Base NoSQL database, we can solve the issues of storage, access and exchange of information between devices. In particular, the use of software provided by Google greatly facilitates the integration of the developed application with additional products such as GoogleMaps, GeoFire or GoogleTranslate. Such integration allows increasing the functionality of the PathFinder application and expanding the reach of the audience. It is achieved by adding simultaneous translation of information added to the application.

\section{Conclusions}

It is possible to estimate the increase in tourism due to the usage of the developed software product only indirectly, using data from J'son\& Partners Consulting on the fact that in 2020 the sales of smartphones increased by $70 \%$ compared to 2016 , and the average traffic of mobile users is also growing (Fig. 4) [9].

The developed mobile application should be one of many similar developments that would allow the most complete and varied satisfaction of the demand of tourists and ensure the creation of new tourist brands in Russia, thus increasing the steady interest in tourism in allRussian regions [9].

The situation that has developed recently both in Russia and around the world requires the attraction of new technologies to the sphere of Russian tourism. The creation of an information space will reduce the cost while improving the quality of tourism services and increase the volume of tourism in the regions [10]. 


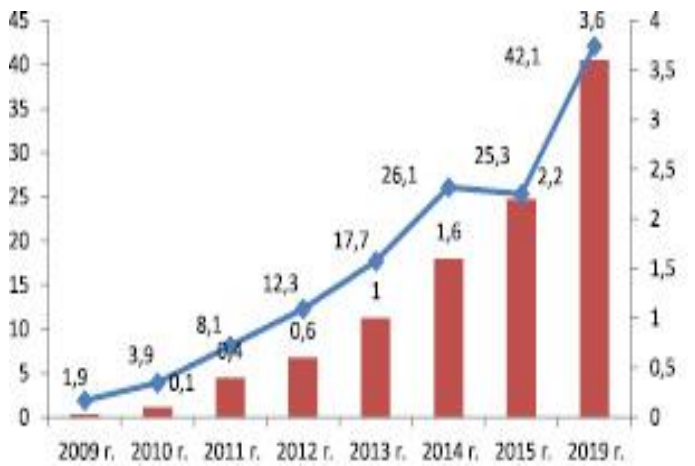

Average traffic per active user of mobile data transmission per month, GB/month Smartphone sales, million units

Fig. 4. The volume of the Russian smartphone market (million units) and the average traffic per active user of mobile data transmission per month (GB/month) [9]

The "Pathfinder" mobile application will provide users not only with a convenient and modern interface for planning their pastime and forming individual thematic routes, but also allow them to take a direct part in filling the application with content about even the most remote and unknown, but no less interesting places in Russia.

\section{References}

1. L.M. Kapustina, V.V. Vyazovskaya, Competitiveness of countries in the world market of tourist services (2017)

2. Richard S. Aquino, Michael Luke, Heike A. Schenze, Journal of Hospitaliti and Turism Management, 37 (2018)

3. Firebase messaging cloud, https://docs.microsoft.com/

4. Firebase, Cloud data storage, https://console.firebase.google.com/.

5. V.V. Voevodin, N.N. Popova, Programming and Computer Software, 3 (2019)

6. M.A. Alasheev, I.B. Bresler,V.L. Lyaskovsky, Izvestiya RAN. Control theory and systems, 2 (2020)

7. N.E. Surkova, A.V. Ostroukh, Methodology of structural design of information systems, Krasnoyarsk: Research and Innovation Center (2014)

8. V.N. Kasyanov, T.A. Zolotyhin, D.S. Gordeev, Programming and Computer Software, 4 (2019)

9. E.V Vishnevskaya., T.B. Klimova, Y.V., Fundamental research, 4 (2016)

10. M.Yu. Khavinson, M.P. Kulakov, E.Ya. Frisman, Computer research and modeling, 5 (2016) 